\title{
Analysis of application for situational teaching method in tourism English teaching
}

\author{
Jing Li \\ Qinhuangdao Institute of Technology, Qinhuangdao, Hebei, China
}

\begin{abstract}
Faced with China's English teaching problems today, it is not enough to just know that the situational teaching method can be effectively applied in a wide range of English teaching, but there is a must to embody the specific application value of the situational teaching method. This paper first analyzes tourism English teaching in China through establishing the quantifiable group-index hierarchical structure model to obtain the optimal training program of China's tourism English talents, and then carries out a detailed analysis of the application and role of the situational teaching method in training of the tourism English ability to obtain the specific application scope and application value of the situational teaching method in the tourism English teaching.
\end{abstract}

Keywords: situational teaching method; tourism English teaching; quantifiable analysis

\section{INTRODUCTION}

With the upgrading of China's national strength, the international role is also not overlooked. Today, China's economy is the most important part in the world economy and trade, which makes China's economy and society develop towards diversification and cross-culture. China's tourism industry has a rapid development, because of vast territory and abundant resources and a long history of China. Therefore, China has abundant natural heritages and cultural heritages. China has many well-known natural and cultural heritages, and many foreign tourists who are attracted by its reputation, so the potential trend is to cultivate China's tourism English talents.

Due to the huge differences between Chinese and English, it is very important to cultivate the practical ability of tourism English talents. As China's second application language and the world's most popular language, English obtains a very high attention in our country. Nowadays, English still accounts for a large proportion in China's talent training program. English achieves a higher popularization range, and the education quality basically meets the requirements. However, the training of the practical and effective application ability of the talents is not enough. With advance of science and technology, there are more and more English teaching methods. The concept of English teaching under the situational teaching mode is in line with the current basic needs in China, so it is widely recognized and respected.

This paper will carry out a detailed quantitative weighting evaluation analysis, and research the actual application value of the situational teaching method in tourism English teaching through establishing the quantifiable hierarchical structure model based on the problems of tourism English education in China.

\section{RELEVANT RESEARCH OF APPLICATION FOR SITUATIONAL TEACHING METHOD IN ENGLISH TEACHING}

Due to the huge differences between Chinese and English, it is very important to cultivate the practical ability of tourism English talents. As China's second application language and the world's most popular language, English obtains a very high attention in our country. Nowadays, English still accounts for a large proportion in China's talent training program. English achieves a higher popularization range, and the education quality basically meets the requirements. However, the training of the practical and effective application ability of the talents is not enough, mainly because the countrymen pay attention to English education, and more and more English educational institutions are built, but there is a difference between guiding philosophy and reality of English education, and 
the training purpose is not clear. Therefore, in recent years, English education in China is aimed at examination, with the evaluation criteria of a high score, so that English ability of many talents deviates from usability. However, based on the current international situation in China, there is a need to highlight the usefulness of English education, and the situational teaching method can preferably cultivate the practical English ability of talents, so the research of English teaching under the perspective of situational teaching is the current hot spot.

In recent years, the research and application for the situational teaching method in English teaching has been carried out in many fields, including the research of the situational teaching method in business English teaching. For example, the paper published by Luo Caiyan in 2012 carries out a detailed discussion of the role and effect of the situational teaching method in oral English teaching; in 2007, Han Ning analyzed the specific application situation of the situational teaching method in business English based on the specific individual cases; there are also many applied researches of the situational teaching method in the specific English teaching. For example, in 2013, Wang Guli illustrated the application for the situational teaching method to improve English reading, listening and speaking abilities. In addition to the above-mentioned researches, there are also numerous researches of application for the situational teaching method in the specific English teaching. For example, in 2011, Liu Xiaotang described the actual application for the situational teaching method in Discussion of Situational Teaching Method in Higher Vocational Tourism English Teaching. However, there are very few researches of the actual value of application for the situational teaching method in tourism English teaching and even the entire English teaching. However, faced with China's English teaching problems today, it is not enough to just know that the situational teaching method can be effectively applied in a wide range of English teaching, but there is a must to embody the specific application value of the situational teaching method, in order to efficiently allocate teaching resources and develop teaching programs to a maximum extent. This paper carries out the applied research of the situational teaching method in the tourism English teaching through establishing the group-index hierarchical structure model, thus giving out its definitive application value.

\section{QUANTIFIABLE WEIGHTING EVALUATION RESEARCH OF TOURISM ENGLISH TEACHING IN CHINA}

The group-index evaluation method of the quantifiable weighting hierarchical structure model has a very effective application in many fields, which can empower according to a large number of references and experience of relevant experts, thus finding out practical solutions. Based on the above content, faced with China's English teaching problems today, it is not enough to just know that the situational teaching method can be effectively applied in a wide range of English teaching, but there is a must to embody the specific application value of the situational teaching method, in order to efficiently develop teaching programs to a maximum extent. Therefore, this paper establishes the group-index hierarchical structure model based on the quantifiable analysis to research the tourism English teaching. In order to analyze the specific practical value of the situational teaching method in tourism English teaching in China, there is a need to first cultivate the specific English ability in the tourism English teaching, and first establishes a quantifiable group-index hierarchical structure model for the tourism English teaching in China, and then quantify all kinds of influence factors and programs, and establish the relations between the target layer, criterion layer and scheme layer.

Target layer: tourism English teaching in China.

Criterion layer: influence factors of the program. $x_{1}$ is the practical oral communication skills with travelers; $x_{2}$ is the ability to store multiple dimension of knowledge; $x_{3}$ is the ability to explain the culture of passengers; $x_{4}$ is the role playing ability; $x_{5}$ is the actual service capability.

Scheme layer: $y_{1}$ is the cultivation of practical oral ability; $y_{2}$ is the cultivation the ability to reserve multi-cultural knowledge; $y_{3}$ is the cultivation of the ability of using knowledge activation; $y_{4}$ is the training of business processing ability, thus obtaining the hierarchical structure, as shown in Figure 1.

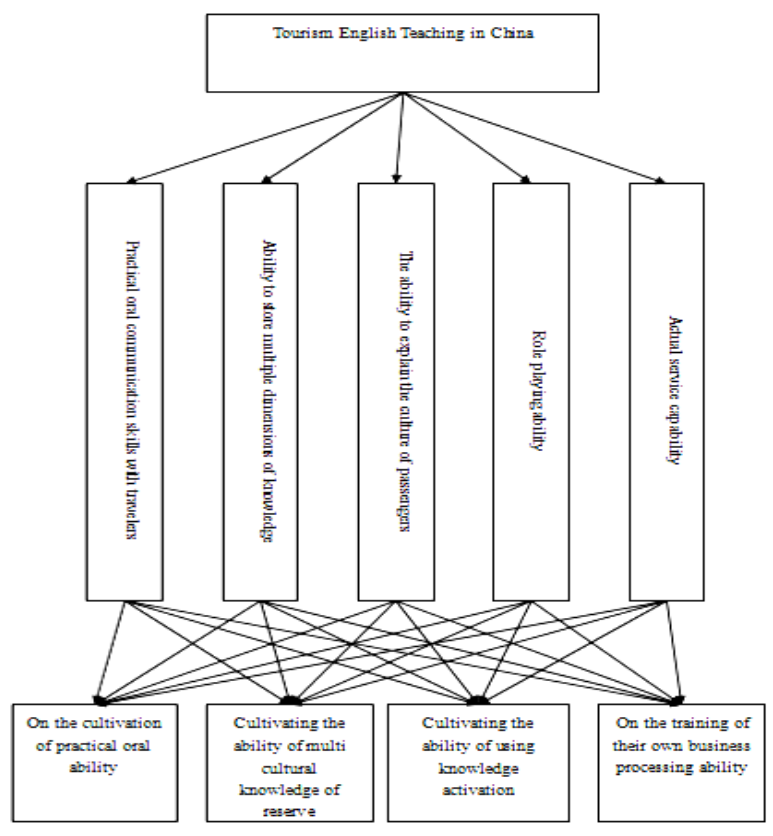

Figure 1. Hierarchical structure

According to the experience of a large number of 
experts, and with reference to a large amount of literatures, the scale from 1 to 9 is shown in Table 1 .

Table 1. 1-9 scale table

\begin{tabular}{|l|l|}
\hline Scale $a_{i j}$ & Definition \\
\hline 1 & i factor is equally important to $\mathrm{j}$ factor \\
\hline 3 & i factor is slightly important than $\mathrm{j}$ factor \\
\hline 5 & i factor is more important than $\mathrm{j}$ factor \\
\hline 7 & i factor and $\mathrm{j}$ factor are very important \\
\hline 9 & i factor and $\mathrm{j}$ factor are absolutely important \\
\hline $2,4,6,8$ & $\begin{array}{l}\text { Scale values corresponding to the intermediate } \\
\text { state in above judgment }\end{array}$ \\
\hline Reciprocal & $\begin{array}{l}\text { If i factor and } \mathrm{j} \text { factor are weak, the judgment } \\
\text { value is a reciprocal }\end{array}$ \\
\hline
\end{tabular}

According to the formula $C I=\frac{\lambda_{\max }-n}{n-1}$, calculate $C I$ and obtain the analysis consistency, and finally obtain the reasonable consistency of $C$, that is, the judgment matrix passes the consistency test by the use of the above principle.

$$
\begin{aligned}
C_{1} & =\left\{\begin{array}{cccc}
1 & 2 & 3 & 3 \\
1 / 2 & 1 & 2 & 2 \\
1 / 3 & 1 / 2 & 1 & 1 \\
1 / 3 & 1 / 2 & 1 & 1
\end{array}\right\}, C_{2}=\left\{\begin{array}{cccc}
1 & 4 & 2 & 1 / 3 \\
1 / 4 & 1 & 1 / 2 & 4 \\
1 / 2 & 2 & 1 & 2 \\
3 & 1 / 4 & 1 / 2 & 1
\end{array}\right\}, \\
C_{3} & =\left\{\begin{array}{cccc}
1 & 1 / 2 & 3 & 4 \\
2 & 1 & 4 & 5 \\
1 / 3 & 1 / 4 & 1 & 1 / 2 \\
1 / 4 & 1 / 5 & 2 & 1
\end{array}\right\}, C_{4}=\left\{\begin{array}{cccc}
1 & 3 & 3 & 2 \\
1 / 3 & 1 & 1 & 3 \\
1 / 3 & 1 & 1 & 3 \\
1 / 2 & 1 / 3 & 1 / 3 & 1
\end{array}\right\}, \\
C_{5} & =\left\{\begin{array}{cccc}
1 & 2 & 3 & 2 \\
1 / 2 & 1 & 1 / 2 & 1 / 2 \\
1 / 3 & 2 & 1 & 1 / 2 \\
1 / 2 & 2 & 2 & 1
\end{array}\right\}
\end{aligned}
$$

To test the reasonableness of weight value by the use of consistency indicators:

$C I=\frac{\lambda_{\max }-n}{n-1}, \quad C R=\frac{C I}{R I}$

RI values are shown in Table 2 .

Table 2. RI values

\begin{tabular}{|l|l|l|l|l|l|l|l|l|l|l|l|}
\hline $\mathrm{n}$ & 1 & 2 & 3 & 4 & 5 & 6 & 7 & 8 & 9 & 10 & 11 \\
\hline $\mathrm{RI}$ & 0 & 0 & 0.58 & 0.90 & 1.12 & 1.24 & 1.32 & 1.41 & 1.45 & 1.49 & 1.51 \\
\hline
\end{tabular}

Obtain the judgment matrix $A, \lambda^{(0)}{ }_{\text {max }}=4.15, R I=0.9$

$C I=\frac{4.15-4}{4-1}=0.24$

$C R=\frac{C I}{R I}=\frac{0.024}{0.90}=0.027<0.1$

The result is smaller than 0.1 , indicating that the consistency test result of $A$ is reasonable, and $A$ is allowed to move within the permissible range, and the eigenvector solved by $A$ matrix can be described as a weight vector. After the consistency test of the judg- ment matrix, the calculation results from the target layer to the scheme layer can be obtained, as shown in Figure 2.

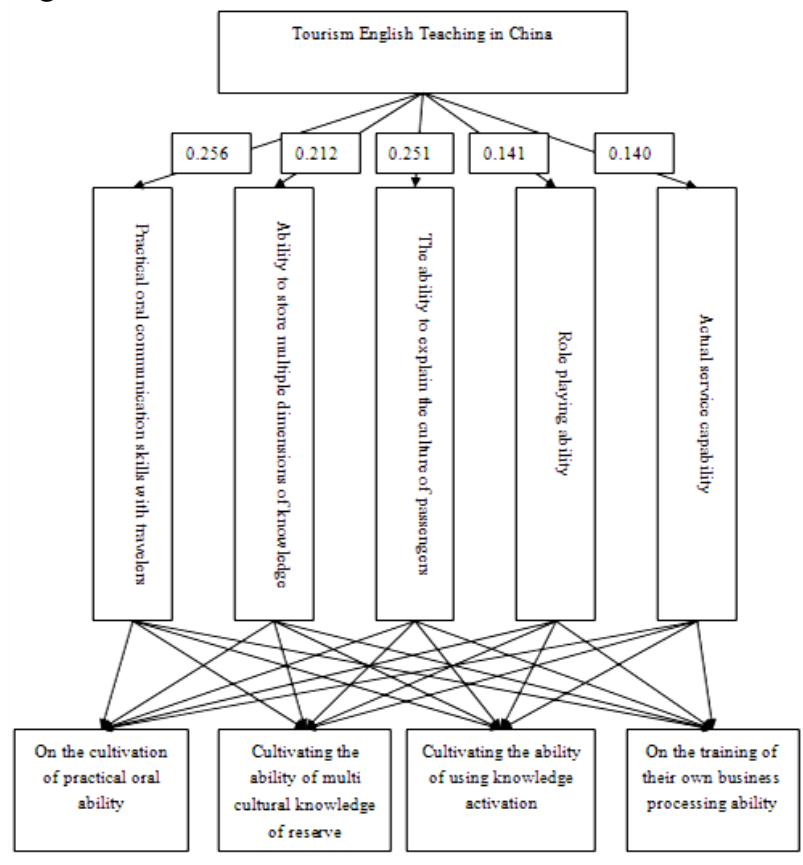

Figure 2. Calculation results from the target layer to the scheme layer

The calculation structure is as follows:

$$
\begin{aligned}
i^{(1)} & =\left(i_{1}^{(1)}, i^{(1)}{ }_{2}, i^{(1)}{ }_{3}, i^{(1)}{ }_{4}, i^{(1)}{ }_{5}\right) \\
& =\left\{\begin{array}{lllll}
0.203 & 0.163 & 0.224 & 0.294 & 0.220 \\
0.302 & 0.395 & 0.232 & 0.220 & 0.333 \\
0.311 & 0.344 & 0.323 & 0.211 & 0.222 \\
0.194 & 0.188 & 0.221 & 0.277 & 0.222
\end{array}\right\}
\end{aligned}
$$

$$
\begin{aligned}
i & =i^{(1)} i^{(0)} \\
& =\left\{\begin{array}{lllll}
0.203 & 0.163 & 0.224 & 0.294 & 0.220 \\
0.302 & 0.395 & 0.232 & 0.220 & 0.333 \\
0.311 & 0.344 & 0.323 & 0.211 & 0.222 \\
0.194 & 0.188 & 0.221 & 0.277 & 0.222
\end{array}\right\}\left\{\begin{array}{l}
0.248 \\
0.242 \\
0.241 \\
0.181 \\
0.128
\end{array}\right\}=\left\{\begin{array}{l}
0.336 \\
0.243 \\
0.220 \\
0.201
\end{array}\right\}
\end{aligned}
$$

Based on the analysis of the tourism English teaching in China through establishing the quantifiable group-index hierarchical structure model, the ability of the tourism English talents should be trained from many aspects, thus obtaining the following several aspects through conclusion and statistics, that is, practical oral communication skills with travelers, ability to store multiple dimension of knowledge, ability to explain the culture of passengers, role playing ability and actual service capability. The role playing ability and actual service capacity are mainly manifested by the practical organizational ability of the tour guide, ability to deal with random events, real-time service capability for passenger catering and accommodation 
consumption. After the weight analysis, the optimal training programs for tourism English talents in China are the cultivation of practical oral ability, cultivation of the ability to store multi-cultural knowledge, cultivation of the ability of using knowledge activation, and training of business processing ability, with the weight of respectively $0.336,0.243,0.220$ and 0.201 . The degree of importance and sequence of ability training depends on the size of the weight value.

\section{RESEARCH OF PRACTICAL APPLICATION FOR SITUATIONAL TEACHING METHOD IN TOURISM ENGLISH TEACHING}

According to the above content, in order to cultivate excellent talents of tourism English, there is a need to first cultivate the practical oral ability, the ability to store multi-cultural knowledge, the ability of using knowledge activation, and the business processing ability. The cultivation of the practical oral ability and the ability to store multi-cultural knowledge is more important, the latter two are the second. The situational teaching method stresses the integration with real life, rather than the formulary education, which is focused on the situation. How to apply for the situational teaching method in the cultivation of the tourism English ability is shown in Figure 3.

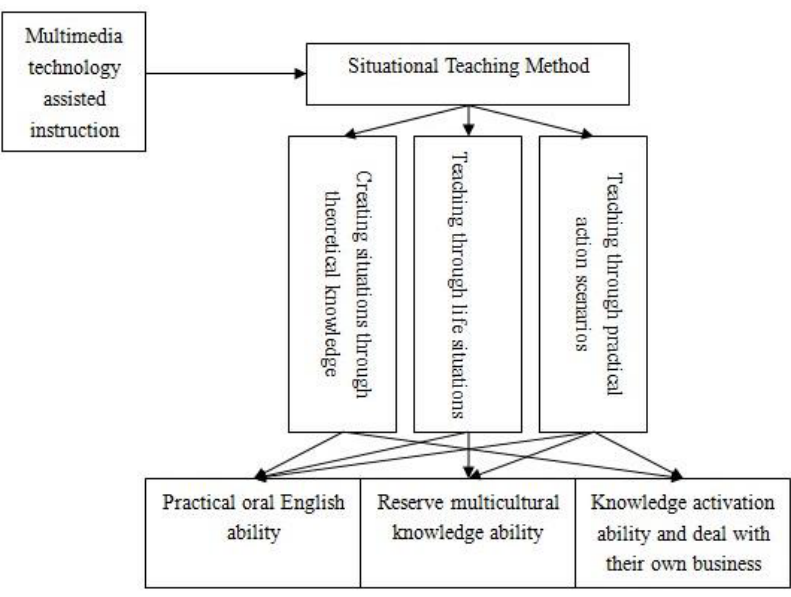

Figure 3. Application for the situational teaching method in cultivation of tourism English ability

As can be seen from Figure 3, under the premise of the assisted teaching of multimedia technology, the main application methods of the situational teaching method are as follows: to provide training data by constructing the relevant situations through the theoretical knowledge, to provide training data through contacting familiar situations in life and the situation with feelings, and to train through organizing practical action scenarios. Such situational teaching can not only improve teaching efficiency, but also actively cultivate students' interest, so as to form healthy educational interactive learning system. These three ways can effectively practice the practical oral ability, while the latter two ways are more effective for the cultivation of the ability to store knowledge, the way of combination with the theory and practice is the most effective for the cultivation of using knowledge activation and business processing ability.

\section{CONCLUSION}

This paper first analyzes the tourism English teaching in China through establishing the quantifiable group-index hierarchical structure model. The result shows that, to cultivate excellent talents of tourism English, there is a need to first cultivate the practical oral ability, the ability to store multi-cultural knowledge, the ability of using knowledge activation, and the business processing ability. This paper later carries out a detailed analysis of the application and role of the situational teaching method in the cultivation of tourism English ability, and obtains the specific application scope and application value. To find out the reasonable indicators through the actual research, and then carry out multi-index weight analysis will further enhance the evaluation of the precision of application value of situational teaching method in tourism English teaching.

\section{REFERENCES}

[1] Xu Manyun, Fang Wei. 2012. Application for situational teaching method in college oral English teaching. Jour nal of Hubei Radio and TV University, (01).

[2] Guan Di. 2014. Analysis of introduction of "culture" into the classroom of tourism English teaching. Tourism Overview (second half), (12).

[3] Zong Xiaohui. 2014. Discussion of problems and innovation of tourism English teaching in China. Netizen World, (15).

[4] Wang Xiaoyu. 2014. Reform of tourism English teaching oriented by professional ability. Teaching (Higher Education Forum), (08).

[5] Wang Yan. 2015. Analysis of application for listening and speaking-led situational teaching method in English teaching. Road to Success, (32).

[6] Li Jingjing. 2015. Research of situational teaching method in vocational English Teaching. Campus English, (31).

[7] Hao Zhiyan. 2015. Discussion of application for situational teaching method in senior English. Teen Diary (Education and Teaching Research), (12).

[8] Li Hainan, Lei Ranran. 2015. Role of situational teaching method for learning English words by junior middle school students. Education and Teaching Forum, (44).

[9] Wu Yan. 2015. Application for situational teaching method in vocational English teaching. Guide to Business, (23).

[10] Zhan Xing. 2015. Analysis of role of experience teaching in vocational tourism English teaching. Happy Reading, (24). 